\title{
Characterization of an anaerobic fungus from llama faeces
}

\author{
Femke D. Marvin-Sikkema, ${ }^{*}$ Greetje A. Lahpor, Marjan N. KraAk, \\ Jan C. GotTschal and Rudolf A. Prins \\ Department of Microbiology, University of Groningen, Kerklaan 30, 9751 NN Haren, The Netherlands
}

(Received 21 January 1992; revised 22 May 1992; accepted 22 June 1992)

\begin{abstract}
An anaerobic fungus was isolated from llama faeces. Based on its morphological characteristics, polyflagellated zoospores, extensive rhizoid system and the formation of monocentric colonies, the fungus is assigned to the genus Neocallimastix. Neocallimastix sp. L2 is able to grow on several poly-, oligo- and monosaccharides. It differs from other Neocallimastix isolates in its inability to ferment inulin. Neocallimastix sp. $\mathrm{L} 2$ requires $\mathrm{CO}_{2}$ for growth. In the presence of $100 \% \mathrm{CO}_{2}$ in the gas phase glucose is fermented to $\mathrm{H}_{2}, \mathrm{CO}_{2}$, formate, acetate, lactate, succinate and ethanol (33.8, 15.4, 74.3, 69.2, 26.7, 8.2, and $28 \cdot 7 \mathrm{mmol}$ per 100 mmol glucose, respectively). Reduced sulphur compounds can be used as sulphur source and ammonium or amino acids as nitrogen source. The temperature range for glucose fermentation is from 37 to $42{ }^{\circ} \mathrm{C}$ with an optimum of around $38{ }^{\circ} \mathrm{C}$. The $\mathrm{pH}$ range for glucose fermentation is from $\mathrm{pH} 6$ to $\mathrm{pH} 8$ with a broad optimum between $\mathrm{pH} 6.5$ and $\mathrm{pH} 7.5$. The zoospores of Neocallimastix sp. L2 contain ribosomal 'globules' and hydrogenosomes. In the kinetosomes of the zoospores spurs, scoops and skirts are visible. In both the rhizoids and the sporangia 'crystal bodies' and hydrogenosomes are present. Mitochondria were not detected in either of these life stages.
\end{abstract}

\section{Introduction}

Anaerobic fungi inhabit certain regions of the alimentary tract of many herbivorous mammals (Orpin \& Joblin, 1988; Teunissen et al., 1991). The importance of anaerobic fungi in herbivore digestion remains unclear, but their capacity to produce large amounts of fibredigesting enzymes (Williams \& Orpin, 1987) and their ability to digest up to half of the dry weight of plant tissue in vitro (Lowe et al., 1987) suggest that they contribute significantly to plant fibre digestion in herbivores.

A considerable number of anaerobic fungi have been isolated from the alimentary tract, saliva and faeces of many different herbivores. In dried faeces anaerobic fungi can survive for several months, possibly in some sort of resistant form (Milne et al., 1989). All anaerobic fungi have been assigned to the family of the Neocallimasticaceae of the Spizellomycetales (Chytridiomycetes) (Barr, 1988). Within this family six genera have been recognized: Neocallimastix (Heath et al., 1983; Orpin, 1975; Orpin \& Munn, 1986), Piromyces (previously Piromonas) (Breton et al., 1991; Li et al., 1990; Orpin, 1977a), Caecomyces (previously Sphaeromonas) (Orpin, 1976; Gold et al., 1988), Anaeromyces (Breton et al., 1990), Orpinomyces (Barr et al., 1989) and Ruminomyces

* Author for correspondence. Tel. 3150632169 ; fax 3150635205 .
(Ho et al., 1990), which differ from each other primarily in the number of flagella attached to their zoospores and in the appearance of their thallus. Other morphological characteristics, such as shape and size of sporangia and zoospores, have been used in the characterization of anaerobic chytridiomycetes (Barr et al., 1989; Breton et al., 1989, 1990, 1991; Lowe et al., 1987; Orpin, 1975, 1976, 1977a; Wubah et al., 1991).

The ultrastructure of several species of the genera Neocallimastix, Piromyces and Caecomyces, and one species of the genus Orpinomyces (Li et al., 1991), has been studied. Differences were found in the structure of the implanting of the flagella (flagellar pole) and the distribution of organelles in the zoospore (Gold et al., 1988; Li et al., 1990, 1991; Munn et al., 1988).

Carbohydrate utilization and fermentation products have been studied for many strains of different genera (Breton et al., 1989, 1990, 1991; Kostyukovsky et al., 1991; Mountfort \& Asher, 1985; Orpin, 1975, 1976, 1977 b, Orpin \& Letcher, 1979; Phillips \& Gordon, 1988; Theodorou et al., 1988).

Although intergeneric differences have been found in carbohydrate utilization patterns, such differences cannot be used in distinguishing between strains. The fermentation products $\mathrm{H}_{2}, \mathrm{CO}_{2}$, formate, acetate, lactate and ethanol were reported for all strains tested; formate production by Neocallimastix patriciarum is doubtful 
(Marvin-Sikkema et al., 1990). Many strains also produced succinate (Breton et al., 1989, 1990, 1991; Marvin-Sikkema et al., 1990; Orpin \& Joblin, 1988). Less attention has been paid to other physiological characteristics. Detailed studies of the ultrastructure and physiology of the anaerobic fungi are necessary to improve our understanding of the role of these fungi in their natural environment and their relationship towards each other.

In this paper we describe both metabolic and morphological characteristics of a Neocallimastix strain recently isolated from llama faeces (Marvin-Sikkema $e t$ $a l ., 1990)$ and discuss its relationship to other described isolates of anaerobic fungi.

\section{Methods}

Isolation and cultivation. Neocallimastix $\mathrm{sp.} \mathrm{L} 2$ was isolated as described by Marvin-Sikkema et al. (1990) from freshly collected faeces from a llama (Lama guanicoe glama) that was kept at the Rowett Research Institute, Aberdeen, UK, and was fed a diet containing approximately, $50 \%$ hay, 30\% barley grain, $9 \%$ fish meal, $10 \%$ molasses and a supplement $(1 \%)$ of vitamins and minerals. The fungi were grown in a basal medium at $39^{\circ} \mathrm{C}$ with $10 \mathrm{~mm}$-glucose as the carbon and energy source (unless stated otherwise) as described before (Marvin-Sikkema et al., 1990). The organism was subcultured every $2-3 \mathrm{~d}$ in order to avoid cell death. Stock cultures were preserved as described by Teunissen et al. (1991).

Zoospore isolation. A $1.5 \%(\mathrm{w} / \mathrm{v})$ agar layer, containing basal medium with $10 \mathrm{~mm}$-glucose, was made and solidified in a $500 \mathrm{ml}$ serum bottle with a butyl rubber stopper. The agar was inoculated with $5 \mathrm{ml}$ of a $48 \mathrm{~h}$ culture of Neocallimastix sp. L2, and after $3-4 \mathrm{~d}$ at $39^{\circ} \mathrm{C}, 20 \mathrm{ml}$ of basal medium with $20 \mathrm{~mm}$-glucose was added. After $2 \mathrm{~h}$ at $39^{\circ} \mathrm{C}$ the liquid medium, containing free zoospores, was collected.

Microscopy. Phase-contrast microscopy was performed with a Carl Zeiss G42-1 10-e Axioscope. For ultrathin-section electron microscopy, cells were grown for $24-48 \mathrm{~h}$ in basal medium without agar. Mycelium was collected by centrifugation ( $10 \mathrm{~min}, 200 \mathrm{~g}$ ), washed with $0.1 \mathrm{M}$ sodium-cacodylate buffer $(\mathrm{pH} 7 \cdot 2)$ and fixed for $1 \mathrm{~h}$ in $3 \%(\mathrm{v} / \mathrm{v})$ glutaraldehyde in $0.1 \mathrm{M}$-sodium-cacodylate buffer $(\mathrm{pH} \mathrm{7.2)})$ at $0{ }^{\circ} \mathrm{C}$. The cells were postfixed for $1 \mathrm{~h}$ in a solution of $1 \%(\mathrm{w} / \mathrm{v}) \mathrm{OsO}_{4}$ and $2.5 \%$ $(w / v) \mathrm{K}_{2} \mathrm{CrO}_{7}$ in the same buffer at room temperature and subsequently poststained in $1 \%(\mathrm{w} / \mathrm{v})$ uranyl acetate. After dehydration in a graded ethanol series $(70-100 \%)$ the cells were embedded in Epon 812 resin, sectioned with a diamond knife on an LKB microtome and examined in a Philips CM10 electron microscope. Zoospores were collected as described above and prefixed with glutaraldehyde $(0.1 \%, \mathrm{v} / \mathrm{v}$, in the medium) for $1 \mathrm{~h}$ at $4{ }^{\circ} \mathrm{C}$. The prefixed zoospores were concentrated by centrifugation ( $5 \mathrm{~min}, 700 \mathrm{~g}$ ) and subsequently postfixed, poststained and embedded as described above.

Growth requirements. Substrates were added to a final concentration of $60 \mathrm{~mm}$-carbon. When growth with nitrogen sources other than ammonium was tested the following nitrogen-containing compounds were added to a final concentration of $5 \mathrm{mM}$-nitrogen: $\mathrm{L}$-arginine, $\mathrm{L}$ aspartate, L-methionine, L-cysteine, L-isoleucine, L-valine, L-tryptophan, L-glutamine, L-glutamate, L-glycine, L-phenylalanine, L-proline, $L$-histidine, $L$-serine, a mixture containing equal concentrations of the dipeptides Ala-Ala, Arg-Glu, Glu-Glu, His-Leu, Leu-Leu, Leu-Pro, Pro-Met and D-Ala-D-Glu, a mixture containing equal concentrations of the tripeptides Ala-Val-Leu, Gly-Gly-Gly, Gly-His-Gly, Gly-ProAla, Gly-Ser-Ala, His-Gly-Gly, His-Pro-Val, Ile-Pro-Ile, Pro-Gly-Gly, Pro-His-Val, Pro-Pro-Gly and Pro-Val-Asp, a mixture containing equal concentrations of the tetrapeptides Ala-Ala-Ala-Ala and ArgPro-Gly-Gly, a mixture containing equal concentrations of the pentapeptides Met-Met-Met-Gly-Gly and metenkephalin (all mixtures obtained from Bachem Feinchemikalien AG, Bubendorf, Switzerland), the proteins bovine serum albumin or casein (nach Hammarsten), nitrate, methylamine, choline, or betaine. In these incubations with different nitrogen sources $\left(\mathrm{NH}_{4}\right)_{2} \mathrm{SO}_{4}$ and cysteine. $\mathrm{HCl}$ were omitted from the medium and $0.5 \mathrm{mM}-\mathrm{Na}_{2} \mathrm{~S}$ was used as the reducing agent. In order to examine the range of sulphur sources which could be used by Neocallimastix sp. L2 the sulphur-containing compounds L-cysteine, L-methionine, $\mathrm{Na}_{2} \mathrm{~S}, \mathrm{Na}_{2} \mathrm{SO}_{3}, \mathrm{Na}_{2} \mathrm{SO}_{4}, \mathrm{Na}_{2} \mathrm{~S}_{2} \mathrm{O}_{3}$, dithiothreitol or elemental sulphur were added to a final concentration of 1 or $10 \mathrm{~mm}$-sulphur. In these incubations cysteine. $\mathrm{HCl}$ and $\left(\mathrm{NH}_{4}\right)_{2} \mathrm{SO}_{4}$ were omitted from the medium, $\left(\mathrm{NH}_{4}\right)_{2} \mathrm{SO}_{4}$ was replaced by $\mathrm{NH}_{4} \mathrm{Cl}$, the sulphates were replaced by their chlorides in the trace element solution and a titanium(III)-NTA reductant, prepared as described by Moench \& Zeikus (1983), was used. In the tests for utilization of nitrogen and sulphur sources $10 \mathrm{~mm}$-glucose was used as the carbon and energy source. All soluble additions were sterilized by membrane filtration $(0.20 \mu \mathrm{m}$ pore diameter). Insoluble additions were autoclaved separately $\left(121^{\circ} \mathrm{C}, 20 \mathrm{~min}\right)$ in suspensions which were added aseptically to the medium. The experiments as described above were performed in $16 \mathrm{ml}$ capacity Hungate tubes containing $10 \mathrm{ml}$ medium and fitted with butyl septum stoppers (Bellco Glass). The tubes were inoculated with $0.5 \mathrm{ml}$ culture. The cultures were subcultured twice and after $7 \mathrm{~d}$, growth was examined by measuring cell protein. Cultures without carbon, nitrogen or sulphur were used as controls.

Temperature and $\mathrm{pH}$ profiles were tested in $130 \mathrm{ml}$ bottles, fitted with butyl rubber septa, containing $100 \mathrm{ml}$ basal medium and $10 \mathrm{mM}$ glucose. After inoculation, samples were taken two or three times a day and were analysed for glucose and fermentation products (expressed as total organic carbon). The $\mathrm{pH}$ profile was tested under an atmosphere of $\mathrm{O}_{2}$-free $\mathrm{N}_{2}$ gas containing $5 \%(\mathrm{v} / \mathrm{v}) \mathrm{CO}_{2}$. Several buffers were used for various $\mathrm{pH}$ ranges: $30 \mathrm{~mm}-\mathrm{MES}$ was used at $\mathrm{pH}$ 5-6, $30 \mathrm{mM}-$ $\mathrm{KH}_{2} \mathrm{PO}_{4} / \mathrm{K}_{2} \mathrm{HPO}_{4}$ was used at $\mathrm{pH}$ 6-7.5 and a $30 \mathrm{~mm}-\mathrm{Tris} / \mathrm{HCl}$ was used at $\mathrm{pH} 7 \cdot 5-8 . \mathrm{NaHCO}_{3}$ was added in different amounts, to avoid changes in $\mathrm{pH}$ caused by the $\mathrm{CO}_{2}$ in the gas phase (Umbreit, 1964).

Chemical analysis. Cell protein content was determined by the Lowry method, using harvested cells washed once with $5 \mathrm{ml} 0.5 \%(\mathrm{w} / \mathrm{v}) \mathrm{NaCl}$. Glucose was determined according to Somogyi (1952). Total organic carbon and cell carbon were analysed with a Shimadzu TC-500 carbon analyser, with biphthalate as a standard. Alcohols (Laanbroek et al., 1984) and short-chain fatty acids, both volatile and non-volatile (Nanninga et al., 1986), were analysed by gas chromatography. Formate was determined by the method of Lang \& Lang (1972). $\mathrm{H}_{2}$ in the gas phase of the cultures was analysed as described by Gerritse et al. (1990).

To detect the presence of cytochromes, cells were grown for $72 \mathrm{~h}$ in the basal medium with $10-\mathrm{mM}$ glucose without resazurin, harvested and washed three times with $20 \mathrm{mM}-\mathrm{KH}_{2} \mathrm{PO}_{4} / \mathrm{K}_{2} \mathrm{HPO}_{4}$ buffer, $\mathrm{pH} 7 \cdot 4$. The cells were disrupted with glass beads (1-2 mm diameter) in the same buffer with $5 \%(\mathrm{w} / \mathrm{v})$ Triton $\mathrm{X}-100$. Cytochromes were detected by recording a $\mathrm{KF}_{3}(\mathrm{CN})_{6}$-oxidized/dithionite-reduced spectrum with an Aminco DW-2a UV/VIS spectrophotometer.

In order to measure maximum oxygen consumption rates, cells were cultured statically for $4 \mathrm{~d}$ in basal medium with $10 \mathrm{~mm}$-glucose as carbon and energy source, with $2 \% \mathrm{O}_{2}$ in the gas phase to induce respiratory activity. Cells were harvested anaerobically and washed twice with a $\mathrm{N}_{2}$-flushed buffer. This buffer, $\mathrm{pH} \mathrm{6.8,} \mathrm{contained} \mathrm{the}$ following (mM): $\mathrm{KH}_{2} \mathrm{PO}_{4} / \mathrm{K}_{2} \mathrm{HPO}_{4} 28, \mathrm{NaCl} 15 \cdot 4,\left(\mathrm{NH}_{4}\right)_{2} \mathrm{SO}_{4}$ 3.4, $\mathrm{CaCl}_{2} \mathbf{0} \cdot 6, \mathrm{MgSO}_{4} \mathrm{0} \cdot 4$. Maximum oxygen consumption rates of washed 

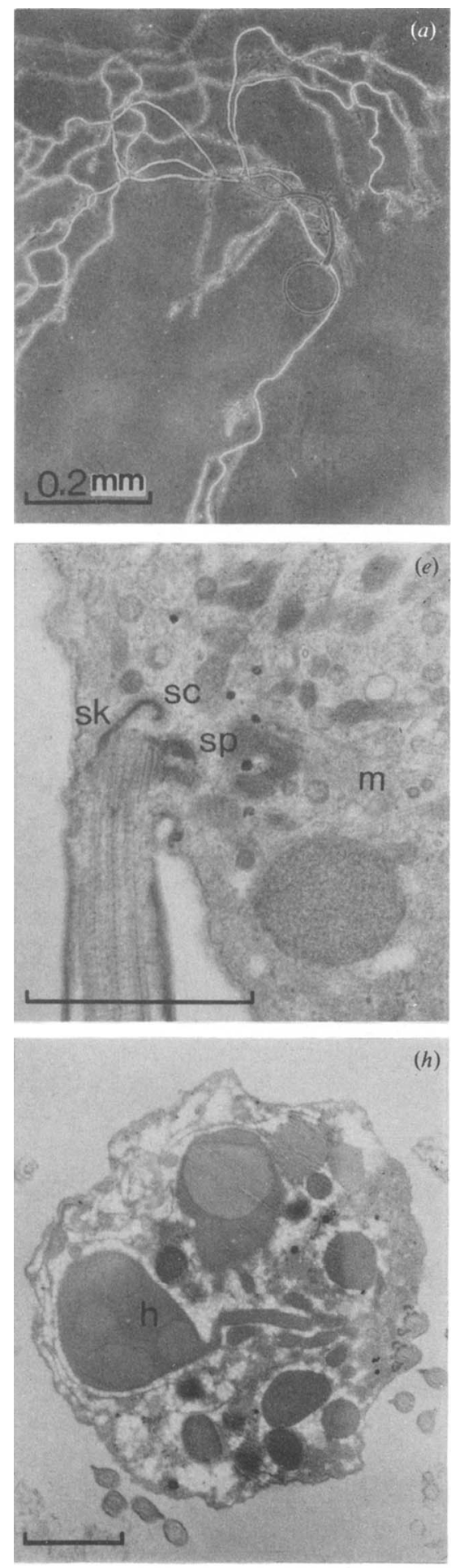
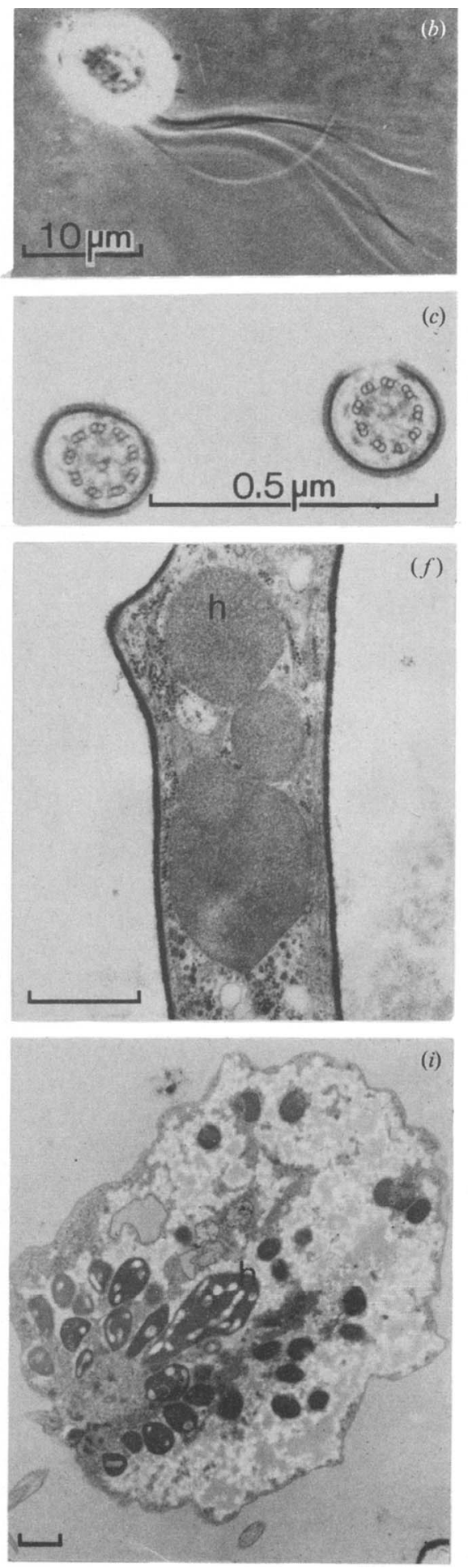
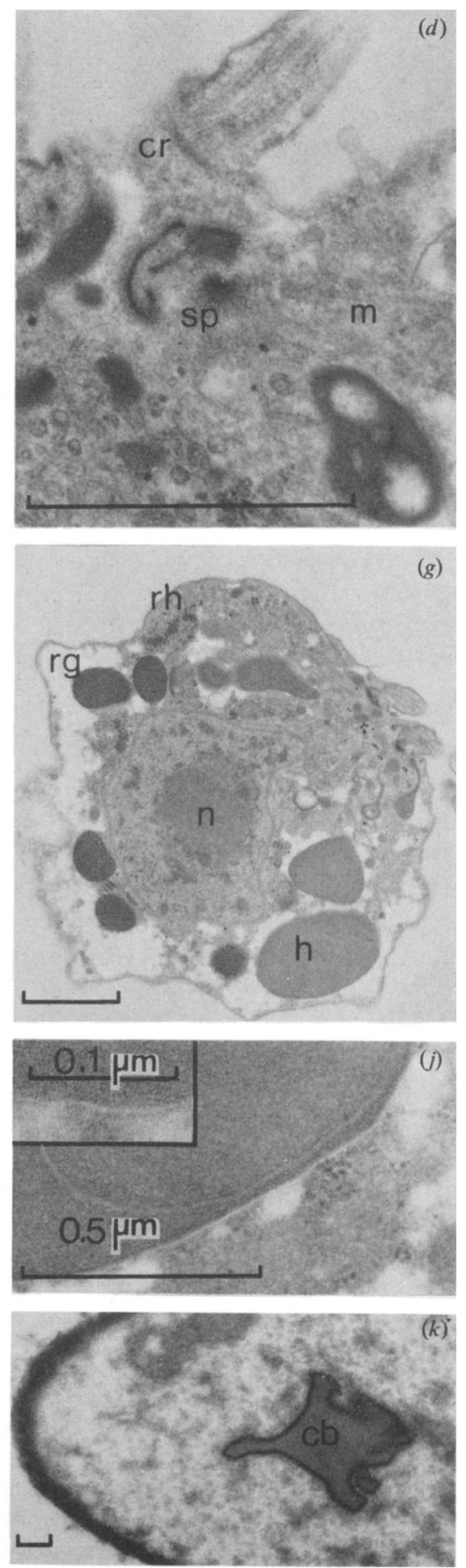

Fig. 1. Morphology and ultrastructure of Neocallimastix sp. L2. (a) Phase-contrast micrograph of sporangium with thallus. (b) Phasecontrast micrograph of zoospore. $(c-k)$ Electron micrographs of thin sections of : $(c)$ flagella; $(d)$ flagellar pole, showing circumflagellar ring (cr), spur (sp), and microtubuli (m); (e) flagellar pole, showing spur (sp), scoop (sc), skirt (sk), and microtubules (m); ( $)$ rhizoid, containing hydrogenosomes $(\mathrm{h})$; $(\mathrm{g})$ overview of a zoospore with hydrogenosomes $(\mathrm{h})$, nucleus $(\mathrm{n})$, and ribosomal aggregates [ribosomal globules ( $\mathrm{rg}$ ) and ribosomal helices (rh)]; $(h)$ zoospore with hydrogenosomes (h), containing internal membranes and possessing branches; $(i)$ zoospore with hydrogenosomes $(h)$ with cytoplasmic regions; $(j)$ hydrogenosome, containing internal membrane, surrounded by a single membrane; $(k)$ rhizoid with 'crystal body' (cb). Bars represent $1 \mu \mathrm{m}$, unless indicated otherwise. 

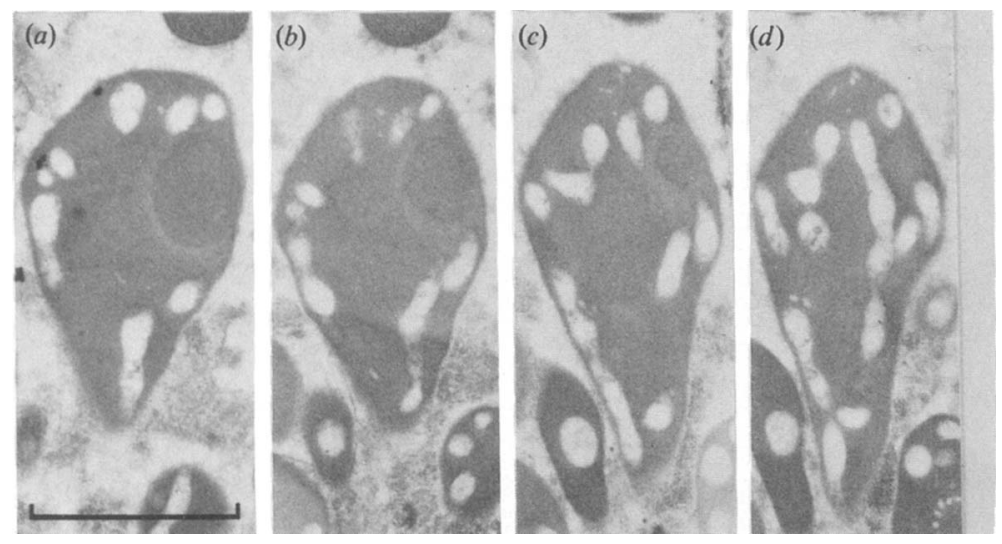

Fig. 2. Electron micrographs of serial sections $(a-d)$ of hydrogenosomes in a zoospore of Neocallimastix sp. L2. Bar represents $1 \mu \mathrm{m}$.

cell suspensions were measured polarographically in a YSI-Biological Oxygen Monitor, using the same buffer containing $200 \mathrm{~mm}$-glucose, in the presence of low oxygen concentrations $(\leqslant 10 \mu \mathrm{M})$ as described in detail elsewhere (Gerritse et al., 1992). All experiments were carried out in triplicate.

\section{Results}

\section{Morphological characterization}

In roll tubes Neocallimastix $\mathrm{sp}$. L2 produces monocentric colonies. In liquid medium its thallus consists of a sporangium with an extensive rhizoid (Fig. 1a). The zoospores are polyflagellated (Fig. $1 b$ ). Electron micrographs of a series of thin sections of these zoospores showed that one zoospore generally possessed nine flagella. The flagella have a typical configuration of $9+2$ axonema (Fig. 1c). A circumflagellar ring surrounds the flagellum near the entrance region of the zoospore (Fig. $1 d)$. In the kinetosomes, spurs, scoops and skirts were visible (Fig. 1e). Struts could not be detected with certainty. Microtubules radiating from the spurs were clearly visible (Fig. $1 d, e$ ). In both mycelium and zoospores, microbodies were observed which appeared very similar to those identified as hydrogenosomes by Yarlett $e t$ al. (1986). In the sporocyst they were detected both in the sporangium and in the rhizoid and are regularly shaped, round to oval (Fig. $1 f$ ). In the zoospores they were located primarily in the vicinity of the kinetosome, mostly as extremely elongated, irregularly shaped organelles, becoming narrower in the direction of the kinetosome (Fig. $1 g, h$ ). In many hydrogenosomes electron-transparent lines and/or cytoplasmic regions were observed (Fig. $1 g, h, i$ ). These cytoplasmic regions formed tubular structures (Fig. 2). The hydrogenosomes were apparently surrounded by a single membrane (Fig. $1 j$ ). In the zoospores two foitms of ribosomal aggregates (Munn et al., 1988) wers detected: helices and globules (Fig. 1g). These'structures are located predominantly opposite the flagellar pole. Struc- tures very similar to those observed by Munn et al. (1988) and referred to as 'crystal bodies' were detected only in the sporocyst (Fig. $1 k$ ). Mitochondria were absent in all life stages.

\section{Metabolism}

Neocallimastix sp. $\mathrm{L} 2$ was able to grow in a $\mathrm{CO}_{2}$-flushed medium only after addition of a reducing agent. When Neocallimastix sp. L2 was grown statically in reduced medium, $\mathrm{O}_{2}$ levels up to $10 \%$ in the gas phase could be applied, without influencing the growth of the fungus. The apparent $K_{\mathrm{m}}$ value and the $V_{\max }$ of $\mathrm{O}_{2}$ utilization of washed cell suspensions with glucose as substrate were $1.0 \pm 0.5 \mu \mathrm{M}$ and $2.0 \pm 0.4 \mathrm{nmol} \mathrm{O}{ }_{2} \cdot \mathrm{min}^{-1}$ (mg cell protein) ${ }^{-1}$, respectively (means $\pm \mathrm{SEM}, n=3$ ). Neocallimastix sp. $\mathrm{L} 2$ was not able to use $\mathrm{NO}_{3}^{-}, \mathrm{SO}_{4}^{2-}, \mathrm{S}_{2} \mathrm{O}_{3}^{2-}$, $\mathrm{Fe}^{3+}$ or fumarate as electron acceptors and no cytochromes could be detected.

Neocallimastix sp. L2 was able to grow on wheat straw, sisal, xylan, soluble starch, amylose, filter-paper, Avicelcellulose, cellulose CF11, raffinose, cellobiose, maltose, sucrose, lactose, glucose, fructose and xylose. No growth was observed on carboxymethylcellulose, inulin, pectin, polygalacturonate, galactose, fucose, ribose, galacturonate, sorbitol, mannitol, glycerol, citrate, pyruvate, malate, L-alanine, L-glutamate, 1-propanol or 2-propanol. In addition to ammonium, amino acids, but not peptides (see Methods for peptides tested), could serve as nitrogen sources. Only reduced sulphur compounds $\left(\mathrm{Na}_{2} \mathrm{~S}\right)$ and sulphur-containing amino acids (L-cysteine and Lmethionine) could be used as sulphur sources. Growth on glucose yielded the following fermentation products (mmol per $100 \mathrm{mmol}$ glucose fermented; means of three experiments \pm SEM) $: \mathrm{H}_{2}(33 \cdot 8 \pm 2 \cdot 0), \mathrm{CO}_{2}$ (estimated from acetate + ethanol - formate-succinate; $15.4 \pm 2.5)$, formate $(74.3 \pm 3.4)$, acetate $(69 \cdot 2 \pm 2.9)$, lactate $(26 \cdot 7 \pm 1 \cdot 5)$, succinate $(8 \cdot 2 \pm 0 \cdot 8)$ and ethanol $(28 \cdot 7 \pm 0 \cdot 16)$. The carbon in the cells was $125 \cdot 0 \pm 4 \cdot 0$ 


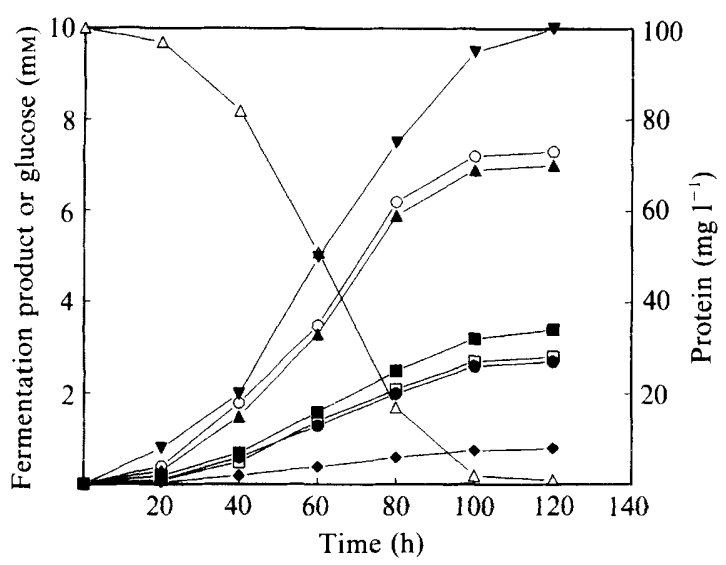

Fig. 3. Fermentation of glucose by Neocallimastix sp. L2. Cells were grown on glucose in basal medium as described in Methods. $\triangle$, Glucose;, $\mathrm{H}_{2} ; \bigcirc$, formate; $\Delta$, acetate; lactate; $\bullet$, succinate; $\square$, ethanol; $\boldsymbol{\nabla}$, cell protein.

mmol per $100 \mathrm{mmol}$ glucose, the carbon recovery was $87 \% \pm 2 \%$ and the oxidation-reduction index of the products was $1 \cdot 16 \pm 0.05$ (assuming a cell composition of $\left.\mathrm{CH}_{1.8} \mathrm{O}_{0.5}\right)$. The formation of the fermentation endproducts was simultaneous (Fig. 3).

The temperature range for glucose fermentation by Neocallimastix sp. L2 was from 37 to $42^{\circ} \mathrm{C}$, with a sharp optimum around $38^{\circ} \mathrm{C}$. The $\mathrm{pH}$ range for glucose fermentation was from $\mathrm{pH} 6$ to $7 \cdot 5$, showing a broad optimum between $\mathrm{pH} 6.5$ and 7.5. Neocallimastix sp. L2 required $\mathrm{CO}_{2}$ for growth. Glucose fermentation rates were $80 \mu \mathrm{mol} \mathrm{l}^{-1} \mathrm{~h}^{-1}$ at $5 \% \mathrm{CO}_{2}$, gradually increasing to $140 \mu \mathrm{mol} \mathrm{l}^{-1} \mathrm{~h}^{-1}$ at $100 \% \mathrm{CO}_{2}$ in the gas phase. In the absence of $\mathrm{CO}_{2}$ in the gas phase no growth was observed.

\section{Discussion}

This study describes morphological and physiological characteristics of an anaerobic fungus isolated from llama faeces. Based on its growth characteristics, i.e. polyflagellated zoospores, extensively branched rhizoids and the production of monocentric colonies, the isolate was assigned to the genus Neocallimastix. The organism previously named Neocallimastix joyonii is a polycentric species (Breton et al., 1989) and has therefore been reclassified as Orpinomyces joyonii ( $\mathrm{Li}$ et al., 1991). All Neocallimastix species described thus far were isolated from the rumen or faeces of ruminant foregut fermenters such as sheep (Orpin, 1975; Lowe et al., 1985), cattle (Barr et al., 1989; Kostyukovsky et al., 1991), reindeer (Orpin et al., 1985), llama and impala (this paper, Milne et al., 1989). Anaerobic fungi isolated from hindgut fermenters were assigned to other genera, i.e. Caecomyces (Gold et al., 1988) and Piromyces (Teunissen et al.,
1991). However, the isolation of a Neocallimastix strain from the tapir (Tapirus terrestris), a hindgut fermenter (F. D. Marvin-Sikkema, unpublished), suggests that the genus Neocallimastix is not restricted to foregut-fermenting herbivores.

When ultrastructural features of Neocallimastix sp. L2 were compared with those described for other strains of Neocallimastix and other genera of anaerobic fungi, the following can be concluded. So-called 'crystal bodies' and microbodies (hydrogenosomes according to Yarlett et al., 1986) have been observed in the vegetative stage of all members of the Neocallimasticaceae studied so far (Gold et al., 1988; Munn et al., 1988). In zoospores of all genera they are located around the flagella pole (Gold et $a l ., 1988)$. The location of these structures close to the motility apparatus was also found in the rumen holotrichs Dasytricha ruminantium and Isotricha sp. (Yarlett et al., 1981, 1983). In zoospores of Neocallimastix sp. L2 the hydrogenosomes appear to be very elongated towards the flagella pole, with a bulb at the opposite side. They also appear irregularly shaped and in many cases seem to contain regions of cytoplasm (Figs $1 i$ and 2). It could not be decided with certainty whether these structures are indeed invaginations of the cytosol. Similar regions have been found in Piromyces mae and Neocallimastix hurleyensis (Li et al., 1990; Webb \& Theodorou, 1988, 1991). Hydrogenosomes with such structures have been termed megahydrogenosomes ( $\mathrm{Li}$ et al., 1990). The internal electron-transparent lines in some of the hydrogenosomes of Neocallimastix sp. L2 seem to be identical with the lines which were observed around hydrogenosomes in Pyromyces dumbonica (Li et al., 1990). The presence of a single membrane around hydrogenosomes of Neocallimastix sp. L2 is in contrast to the double membranes around hydrogenosomes of anaerobic protozoa (Benchimol \& De Souza, 1983) and supports the hypothesis of Cavalier-Smith (1987), that hydrogenosomes in anaerobic fungi were possibly derived from peroxisomes and did not, as in protozoa, evolve from mitochondria or from symbiotic bacteria. Ribosomal globules and arrays, as observed in all genera and species studied thus far (Heath et al., 1983; Gold et al., 1988; Munn et al., 1988; Webb \& Theodorou, 1988; Li et al., 1990), are also present in Neocallimastix sp. L2. Interestingly, there are clear differences in the location of these structures in zoospores: they are located at the posterior in Neocallimastix frontalis (Heath et al., 1983), at the anterior in Neocallimastix hurleyensis, Piromyces mae and Piromyces dumbonica (Webb \& Theodorou, 1988; Li et al., 1990) and dispersed throughout the cell in all other genera and species (Gold et al., 1988). The anterior location in Neocallimastix sp. L2 emphasizes the relationship of this strain with Neocallimastix hurleyensis. The flagellar apparatus of all anaerobic gut-fungi described so far is 
strikingly similar. Only relatively small variations in some components, i.e. the presence or absence of skirts and struts, appear to exist. These variations are very subtle indeed, sometimes difficult to observe, and there are some contradictory reports on this subject (Munn et al., 1988; Gold et al., 1988). Careful examination of more isolates is needed before the structure of the kinetosome can be used as a trustworthy criterion for classification of anaerobic fungi.

The inability of Neocallimastix sp. L2 to grow in nonreduced medium, the low $V_{\max }$ value of $\mathrm{O}_{2}$ utilization, the absence of cytochromes and the inability to use $\mathrm{NO}_{3}^{-}$, $\mathrm{SO}_{4}^{2-}, \mathrm{S}_{2} \mathrm{O}_{3}^{2-}, \mathrm{Fe}^{3+}$ or fumarate as electron acceptors clearly indicate that this fungus is a strictly fermentative organism. The observed apparent $K_{\mathrm{m}}$ value for $\mathrm{O}_{2}$ $(1.0 \pm 0.5 \mu \mathrm{M})$ is comparable with that found for Dasytricha ruminantium (Lloyd et al., 1983) and Neocallimastix patriciarum (Yarlett et al., 1987) $(1 \cdot 7 \mu \mathrm{M}$ and $4.0 \pm 0.3 \mu \mathrm{M}$, respectively). It can be thus be concluded that Neocallimastix sp. L2 is well adapted to the rumen environment, in which dissolved $\mathrm{O}_{2}$ levels can be up to $1.6 \mu \mathrm{M}$ dissolved $\mathrm{O}_{2}$ (Scott et al., 1983).

Neocallimastix sp. L2 resembles other isolates within the genus Neocallimastix in the range of carbohydrates utilized, but differs in that it is unable to ferment inulin, which is fermented by other Neocallimastix isolates (Phillips \& Gordon, 1988; Theodorou et al., 1988; this paper). As found for Neocallimastix patriciarum (Orpin \& Greenwood, 1986), amino acids can replace ammonium as nitrogen source for growth of Neocallimastix sp. L2. The failure of Neocallimastix sp. L2 to utilize peptides, bovine serum albumin or casein as nitrogen sources may be due to the absence of appropriate uptake mechanisms or an inability to liberate utilizable nitrogen containing compounds from these substrates. The sulphur requirements of Neocallimastix sp. L2 are identical to those found for Neocallimastix patriciarum (Orpin \& Greenwood, 1986). The fermentation products, formed by Neocallimastix sp. L2 are very similar to those formed by other genera, although there are some differences in in their relative proportions (Phillips \& Gordon, 1988; Breton et al., 1989, 1990). Since there are contradictory reports on whether formate is produced by Neocallimastix patriciarum (Orpin \& Munn, 1986; Marvin-Sikkema et al., 1990), formate production cannot be used to characterize Neocallimastix isolates.

It can be concluded from the morphological and physiological characteristics that isolate L2 belongs to the genus Neocallimastix. There are insufficient distinctive morphological and physiological features to decide whether Neocallimastix $\mathrm{sp}$. L2 should be classified as a new species. However, it is clear that although Neocallimastix sp. L2 has many similarities to described isolates, it also has a unique combination of characteristics in which it differs from all other isolates described so far: inability to ferment inulin, extremely sharp temperature optimum, the positioning of the ribosomal globules and arrays at the anterior of the zoospores, and the presence of extremely irregularly shaped hydrogenosomes and megahydrogenosomes in these zoospores. The similarities of this strain from llama faeces to Neocallimastix isolates obtained from other animals, especially Neocallimastix hurleyensis, suggests a lack of herbivore hostspecificity in these fungi.

The authors thank K. Sjollema and $M$. Veenhuis for electron microscopy, J. Zagers and A. Nolle for photography, and C. S. Stewart and A. J. Richardson for technical advice.

\section{References}

BARR, D. J. S. (1988). How modern systematics relates to the rumen fungi. BioSystems 21, 351-356.

BarR, D. J. S., Kudo, H., JAKober, K. D. \& ChenG, K.-J. (1989) Morphology and development of rumen fungi: Neocallimastix sp., Piromyces communis, and Orpinomyces bovis gen. nov., sp. nov. Canadian Journal of Botany 67, 2815-2824.

Benchimol, M. \& DE SouzA, W. (1983). Fine structure and cytochemistry of the hydrogenosomes of Tritrichomonas foetus. Journal of Protozoology 30, 422-425.

Breton, A., Bernalier, A., Bonnemoy, F., Fonty, G., Gaillard, B \& GoUET, P. (1989). Morphological and metabolic characterization of a new species of strictly anaerobic fungus: Neocallimastix joyonii. FEMS Microbiology Letters 58, 309-314.

Breton, A., Bernalier, A., Dusser, M., Fonty, G., GaillardMARTINIE, B. \& GuILlot, J. (1990). Anaeromyces mucronatus nov. gen., nov. sp. A new strictly anaerobic fungus with polycentric thallus. FEMS Microbiology Letters 70, 177-182.

Breton, A., Dusser, M., Gaillard-Martinie, B., Guillot, J., Millet, L. \& Pensier, G. (1991). Piromyces rhizinflata nov. sp., a strictly anaerobic fungus from faeces of the Saharian ass: a morphological, metabolical and ultrastructural study. FEMS Microbiology Letters 82, 1-8.

CAVALIER-SMITH, T. (1987). The simultaneous symbiotic origin of mitochondria, chloroplasts, and microbodies. Annals of the New York Academy of Sciences 503, 55-71.

Gerritse, J., SChUT, F. \& GotTSChal, J. C. (1990). Mixed chemostat cultures of obligately aerobic and fermentative or methanogenic bacteria grown under oxygen-limiting conditions. FEMS Microbiology Letters 66, 87-94.

Gerritse, J., SChUT, F. \& GotTsChal, J. C. (1992). Modelling of mixed chemostat cultures of an aerobic bacterium, Comamonas testosteronii, and an anaerobic bacterium, Veillonella alcalescens: comparison with experimental data. Applied and Environmental Microbiology 58, 1466-1476.

Gold, J. J., HeATH, I. B. \& BAUChOP, T. (1988). Ultrastructural description of a new chytrid genus of caecum anaerobe, Caecomyces egui gen. nov., sp. nov., assigned to the Neocallimasticaceae. BioSystems 21, 403-415.

Heath, I. B., Bauchop, T. \& Skipp, R. A. (1983). Assignment of the rumen anaerobe Neocallimastix frontalis to the Spizellomycetales (Chytridiomycetes) on the basis of its polyflagellate zoospore ultrastructure. Canadian Journal of Botany 61, 295-307.

Ho, Y. W., Bauchop, T., Abdullah, N. \& Jalaludin, S. (1990). Ruminomyces elegans gen. et sp. nov., a polycentric anaerobic rumen fungus from cattle. Mycotaxon 38, 397-405. 
Kostyukovsky, V. A., OKunEv, O. N. \& TaRakanov, B. V. (1991). Description of two anaerobic fungal strains from the bovine rumen and influence of diet on the fungal population in vivo. Journal of General Microbiology 137, 1759-1764.

LaAnbroek, H. J., Geerligs, H. J., Sittsma, L. \& Veldkamp, H. (1984). Competition for sulfate and ethanol among Desulfobacter, Desulfobulbus and Desulfovibrio species isolated from intertidal sediments. Applied and Environmental Microbiology 47, 329-334.

LANG, E \& LANG H. (1972). Spezifische Farbreaktion zum direkten Nachweis der Ameisensäure. Zeitschrift für Analytische Chemie 206, 8-10.

Li, J., Heath, I. B. \& Bauchop, T. (1990). Piromyces mae and Piromyces dumbonica, two new species of uniflagellate anaerobic chytridiomycete fungi from the hindgut of the horse and elephant. Canadian Journal of Botany 68, 1021-1033.

LI, J., Heath, I. B. \& Cheng, K.-J. (1991). The development and zoospore ultrastructure of a polycentric chytridiomycete gut fungus, Orpinomyces joyonii, comb. nov. Canadian Journal of Botany 69, 580589.

Lloyd, D., Williams, A. G., Yarlett, N. \& Hillman, K. (1983). Similarities between rumen ciliates and trichomonads: both possess hydrogenosomes. Protistologica 19, 465.

Lowe, S. E., Theodorou, M. K. \& Trincl, A. P. J. (1985). Growth of anaerobic rumen fungi on defined and semi-defined media lacking rumen fluid. Journal of General Microbiology 131, 2225-2229.

Lowe, S. E., Theodorou, M. K. \& TrincI, A. P. J. (1987). Cellulases and xylanase of an anaerobic rumen fungus grown on wheat straw, holocellulose, cellulose, and xylan. Applied and Environmental Microbiology 53, 1216-1223.

Marvin-Sikkema, F. D., Richardson, A. J., Stewart, C. S. GotTsChal, J. C. \& PRINS, R. A. (1990). Influence of hydrogenconsuming bacteria on cellulose degradation by anaerobic fungi Applied and Environmental Microbiology 56, 3793-3797.

Milne, A., Theodorou, M. K., Jordan, M. G. C., King-Spooner, C. \& TrinCI, A. P. J. (1989). Survival of anaerobic fungi in feces, in saliva, and in pure culture. Experimental Mycology 13, 27-37.

MoENCH, T. T. \& ZeikUs, J. G. (1983). An improved preparation method for a titanium(III) media reductant. Journal of Microbiological Methods 1, 199-202.

MOUNTFoRT, D. A. \& Asher, R. A. (1985). Production and regulation of cellulase by two strains of the anaerobic fungus Neocallimastix frontalis. Applied and Environmental Microbiology 49, 1314-1322.

MunN, E. A., Orpin, C. G. \& Greenwood, C. A. (1988). The ultrastructure and possible relationships of four obligate anaerobic chytridiomycete fungi from the rumen of sheep. BioSystems 22, 6781 .

Nanninga, H. J., Drent, W. J. \& Gottschal, J. C. (1986). Major differences between glutamate-fermenting species isolated from chemostat enrichments at different dilution rates. FEMS Microbiology Ecology 38, 321-329.

ORPIN, C. G. (1975). Studies of the rumen flagellate Neocallimastix frontalis. Journal of General Microbiology 91, 249-262.

ORPIN, C. G. (1976). Studies on the rumen flagellate Sphaeromonas communis. Journal of General Microbiology 94, 270-280.

ORPIN, C. G. (1977a). The rumen flagellate Piromonas communis: its life history and invasion of plant material in the rumen. Journal of General Microbiology 99, 107-117.

ORPIN, C. G. (1977b). The occurrence of chitin in the cell walls of the rumen organisms Neocallimastix frontalis, Piromonas communis and Sphaeromonas communis. Journal of General Microbiology 99, 215 218.

ORPIN, C. G. \& GREeNwOOD, Y. (1986). Nutrition and germination requirements of the rumen phycomycete Neocallimastix patriciarum. Transactions of the British Mycological Society 86, 103-109.
OrPIN, C. G. \& Joblin, K. N. (1988). The rumen anaerobic fungi. In The Rumen Microbial Ecosystem, pp. 129-151. Edited by P. N. Hobson. London: Elsevier Applied Science.

ORPIN, C. G. \& LETCHER, A. J. (1979). Utilization of cellulose, starch, xylan and other hemicelluloses for growth by the rumen phycomycete Neocallimastix frontalis. Current Microbiology 3, 121-124.

ORPIN, C. G. \& MuNN, E. A. (1986). Neocallimastix patriciarum sp. nov., a new member of the Neocallimasticaceae inhabiting the rumen. Transactions of the British Mycological Society 86, 178-181.

ORPIN, C. G., MATHIESEN, S. D., GReENWOOD, Y. \& BliX, A. S. (1985). Seasonal changes in the ruminal microflora of the high-arctic Svalbard Reindeer (Rangifer tarandus platyrhynchus). Applied and Environmental Microbiology 50, 144-151.

PhILLIPS, M. W. \& GoRDON, G. L. R. (1988). Sugar and polysaccharide fermentation by rumen anaerobic fungi from Australia, Britain and New Zealand. BioSystems 21, 377-383.

Scott, R. I., Yarlett, N., Hillman, K., Williams, T. N., Williams, A. G. \& LLOYD, D. (1983). The presence of oxygen in rumen liquor and its effect on methanogenesis. Journal of Applied Bacteriology 55, 143-149.

SomogYI, M. (1952). Notes on sugar determination. Journal of Biological Chemistry 195, 19-23.

Teunissen, M. J., OP Den Kamp, H. J. M., ORPIN, C. G., Huis In't Veld, J. H. J. \& Vogels, G. D. (1991). Comparison of growth characteristics of anaerobic fungi isolated from ruminant and nonruminant herbivores during cultivation in a defined medium. Journal of General Microbiology 137, 1401-1408.

Theodorou, M. K., Lowe, S. E. \& Trinci, A. P. J. (1988). The fermentative characteristics of anaerobic rumen fungi. BioSystems 21, 371-376

UMBREIT, W. W. (1964). Carbon dioxide and bicarbonate. In Manometric Techniques, 4th edn, pp. 18-27. Edited by W. W. Umbreit, R. H. Burris \& J. F. Stauffer. Minneapolis: Burgess Publishing Company.

WEBB, J. \& THEODOROU, M. K. (1988). A rumen anaerobic fungus of the genus Neocallimastix: ultrastructure of the polyflagellate zoospore and young thallus. BioSystems 21, 393-401.

WeBB, J. \& THEODOROU, M. K. (1991). Neocallimastix hurleyensis sp. nov., an anaerobic fungus from the ovine rumen. Canadian Journal of Botany 69, 1220-1224.

Williams, A. G. \& ORPIN, C. G. (1987). Polysaccharide-degrading enzymes formed by three anaerobic fungi grown on a range of carbohydrate substrates. Canadian Journal of Microbiology 33, 418426.

Wubah, D. A., Fuller, M. S. \& AKIN, D. E. (1991). Neocallimastix: a comparative morphological study. Canadian Journal of Botany 69, 835-843.

Yarlett, N., HaNN, A. C., Lloyd, D. \& Williams, A. (1981), Hydrogenosomes in the rumen protozoon Dasytricha ruminantium Schuberg. Biochemical Journal 200, 365-372.

Yarlett, N., HanN, A. C., Lloyd, D. \& Williams, A. G. (1983). Hydrogenosomes in a mixed isolate of Isotricha prostome and Isotricha intestinalis from ovine rumen contents. Comparative Biochemistry and Physiology 74B, 357-364.

Yarlett, N., Orpin, C. G., MunN, E. A., Yarlett, N. C \& GREENWOOD, C. A. (1986). Hydrogenosomes in the rumen fungus Neocallimastix patriciarum. Biochemical Journal 236, 729-739.

Yarlett, N., Rowlands, C., Yarlett, N. C., Evans, J. C. \& LLOYD, D. (1987). Respiration of the hydrogenosome-containing fungus Neocallimastix patriciarium. Archives of Microbiology 148 , $25-28$. 